\title{
Eine religiöse Referenz in einem Europäischen Verfassungsvertrag
}

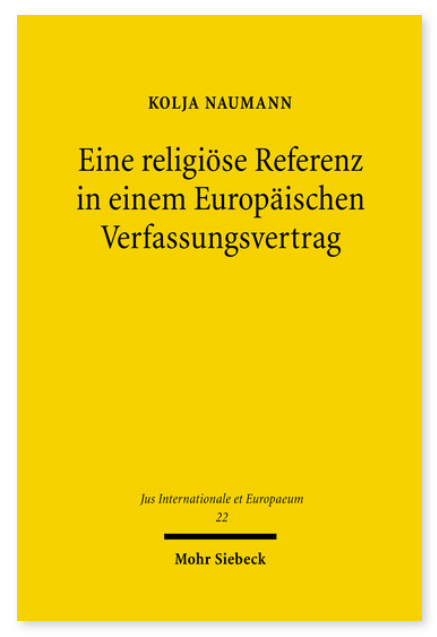

2008. XVII, 281 Seiten. JusIntEu 22

ISBN 978-3-16-151161-5

DOI 10.1628/978-3-16-151161-5

eBook PDF $74,00 €$

ISBN 978-3-16-149704-9

fadengeheftete Broschur 74,00€
Die Aufnahme einer religiösen Referenz oder eines Gottesbezugs in die Präambel war ein zentraler Streitpunkt bei der Ausarbeitung des Europäischen Verfassungsvertrags. Kolja Naumann untersucht ausgehend von verfassungsrechtlichen, völker- und europarechtlichen Überlegungen die rechtlichen Auswirkungen der diskutierten Varianten: einer neutralen Referenz an das religiöse Erbe Europas, einer Hervorhebung des christlichen Erbes oder einer Nennung der Verantwortung vor Gott und den Menschen. Der Autor kommt zu dem Ergebnis, dass sich die religiösen Referenzen weder zur Begründung einer besonderen Bedeutung religiöser Argumente im Unionsrecht noch zur Anerkennung überpositiver Rechtsnormen instrumentalisieren lassen. Die religiöse Referenz in der Präambel des Verfassungsvertrags bringt vielmehr deutlich zum Ausdruck, dass die Europäische Union des 21. Jahrhunderts ihre oft konstatierte 'Religionsblindheit' überwindet und ein freundliches und diskriminierungsfreies Zusammenwirken mit Religions- und Weltanschauungsgemeinschaften entwickelt. Der Autor veranschaulicht, dass die Erwähnung der Bedeutung des Erbes Europas für die Entwicklung der Unionswerte deutlich macht, dass diese im Lichte ihrer begriffsgeschichtlichen Bedeutung ausgelegt werden müssen.

Von diesen Überlegungen ausgehend untersucht Kolja Naumann die Auswirkungen der religiösen Referenz auf die Auslegung der Normen des Verfassungsvertrags und insbesondere auf das sich entwickelnde Religionsverfassungsrecht. Dabei arbeitet er auch die Grenzen dieser Auslegungsfunktion heraus.

Kolja Naumann Geboren 1980; Studium der Rechts- und Politikwissenschaften in Bonn, Paris und Köln; 2007 Promotion; Rechtsreferendar beim OLG Köln.

Jetzt bestellen:

https://mohrsiebeck.com/buch/eine-religioese-referenz-in-einem-europaeischen-verfassungsvertrag-9783161511615?

no_cache=1

order@mohrsiebeck.com

Telefon: +49 (0)7071-923-17

Telefax: $+49(0) 7071-51104$ 